\title{
Changes of farnesoid $X$ receptor and Takeda G-protein coupled receptor 5 following biliary tract external drainage in hemorrhagic shock
}

\author{
LU WANG, HUAI-WU HE, XIANG ZHOU and YUN LONG \\ Department of Critical Care Medicine, Peking Union Medical College Hospital, \\ Peking Union Medical College and Chinese Academy of Medical Sciences, Beijing 100730, P.R. China
}

Received July 2, 2020; Accepted November 26, 2021

DOI: $10.3892 /$ etm.2021.11086

\begin{abstract}
Since biliary tract external drainage (BTED) is increasingly used to treat patients with shock, it is necessary to clarify pathophysiological changes following BTED in hemorrhagic shock (HS). The present study aimed to investigate the effect of BTED on farnesoid X receptor (FXR) and Takeda G-protein coupled receptor 5 (TGR-5) expression in HS. A total of 24 Sprague-Dawley rats were randomly allocated to sham, BTED, HS and HS + BTED groups. Rat models of HS were induced by drawing blood from the femoral artery until a mean arterial pressure of $40 \pm 5 \mathrm{mmHg}$ was achieved and maintained for $60 \mathrm{~min}$. Rat models of BTED were induced by inserting a catheter into the bile duct. The distal end of the bile duct was ligated, and the catheter was passed through the rat flank to allow external collection of bile. Reverse transcription-quantitative PCR, western blotting and immunohistochemistry were performed to detect changes in expression levels of FXR and TGR-5 in the jejunum, ileum and liver. Expression levels of FXR and TGR-5 increased significantly in jejunum and liver following $\mathrm{HS}(\mathrm{P}<0.05)$. BTED significantly decreased expression levels of FXR in the liver $(\mathrm{P}<0.05)$ and TGR-5 in the jejunum, ileum and liver $(\mathrm{P}<0.05)$. In conclusion, expression levels of FXR and TGR-5 increased in HS but BTED decreased expression levels of FXR and TGR-5 in HS.
\end{abstract}

\section{Introduction}

Bile acids serve an important role in the pathophysiology of shock (1). Septic shock can be prevented by bile acids (2). Bile

Correspondence to: Dr Xiang Zhou or Dr Yun Long, Department of Critical Care Medicine, Peking Union Medical College Hospital, Peking Union Medical College and Chinese Academy of Medical Sciences, 1 Shuaifuyuan, Dongcheng, Beijing 100730, P.R. China

E-mail: zx_pumc@126.com

E-mail: ly_icu@aliyun.com

Key words: farnesoid $\mathrm{X}$ receptor, Takeda G-protein coupled receptor 5, biliary tract external drainage, hemorrhagic shock, liver, intestine acids are an important defense mechanism against endotoxins in microorganisms (2). Septic shock induces progressive sclerosing cholangitis (3). Bile acids induce platelet inhibition and fibrinolysis in hemorrhagic shock (HS) (1). High-fat enteral nutrition decreases endotoxins, TNF- $\alpha$ and intestinal permeability in bile duct-ligated rats subjected to HS (4). As the technology becomes more minimally invasive, biliary tract external drainage (BTED) is widely applied in critically ill patients, such as severe acute pancreatitis, malignant biliary obstruction (5-7), acute cholangitis (8-11). In our previous studies, BTED decreased multiorgan dysfunction in HS by affecting enterohepatic circulation of bile pigments (12-15).

Cholic acid is one of the primary components of bile. Like cholochromes, bile acids circulate in the intestine and liver. Bile external drainage directly decreases levels of cholic acid in the intestinal tract and in the liver by disrupting enterohepatic circulation (16). Farnesoid X receptor (FXR) and Takeda G-protein coupled receptor 5 (TGR-5) are the two most common cholic acid receptors $(17,18)$. FXR and TGR-5 serve an important role in the enterohepatic circulation of cholic acid. FXR, a member of the ligand-activated nuclear receptor superfamily, is highly expressed in the liver and gastrointestinal tract (19-21). Bile acids are natural ligands for FXR $(22,23)$. Medications that activate FXR promote liver regeneration in mice following partial hepatectomy (24-26). TGR-5, also known as $\mathrm{G}$ protein-coupled bile acid receptor 1 , is expressed in the liver, lungs, intestine, placenta, gallbladder, ovaries, macrophages, monocytes and brown adipose tissue $(27,28)$. TGR-5 is activated by bile acids, including cholic, chenodeoxycholic, deoxycholic and lithocholic acid (29). TGR-5 protects the liver from bile acid overload during liver regeneration in mice $(30,31)$.

To the best of our knowledge, studies on changes in bile acid receptor expression levels following BTED in shock are limited. Since BTED is increasingly used to treat severe acute pancreatitis and acute cholangitis and shock is common in these patients (32), it is necessary to clarify pathophysiological changes following BTED in shock. Identifying the effect of BTED on expression levels of FXR and TGR-5 in liver and intestinal during HS may provide theoretical support for the application of BTED, as well as novel options, for the treatment of HS. The present study aimed to investigate changes in FXR and TGR-5 expression levels 
following HS by performing reverse transcription-quantitative (RT-q)PCR, western blotting and immunohistochemistry. The effect of BTED on FXR and TGR-5 was also studied.

\section{Materials and methods}

Ethics statement. The present study was approved by the Institutional Animal Care and Use Committee at Peking Union Medical College (Beijing, China). Animal surgical procedures were performed in strict accordance with the guidelines for the care and use of laboratory animals established by the Animal Use and Care Committee of the Beijing Committee on Animal Care.

The animal protocol was designed to minimize pain or discomfort to rats. The rats were acclimatized to laboratory conditions $\left(25^{\circ} \mathrm{C}, 12 / 12\right.$-h light/dark cycle, $50 \%$ humidity, ad libitum access to food and water) for 1 week prior to experimentation. All rats were intraperitoneally anesthetized with $3 \%$ sodium pentobarbital $(50 \mathrm{mg} / \mathrm{kg})$ prior to surgery and decapitation.

Animal model. A total of 24 adult male Sprague-Dawley rats (age, 10 weeks; weight, 250-300 g) were purchased from the Fangyuan Yuan Animal Centre of Beijing. The Chinese People's Liberation Army Military Academy of Medical Sciences was responsible for quality control of rats.

Rats were randomly divided into 4 groups ( $\mathrm{n}=6 /$ group) as follows: Sham, BTED, HS and HS + BTED. Rats in the HS + BTED group were intraperitoneally anesthetized with $3 \%$ sodium pentobarbital $(50 \mathrm{mg} / \mathrm{kg})$. Laparotomy was performed following shaving and sterilization. Catheters were placed in both femoral arteries for blood pressure measurement and blood withdrawal. Bile duct was exposed $1 \mathrm{~cm}$ for BTED. Rats were subjected to HS by withdrawing blood at a rate of $1 \mathrm{ml} / \mathrm{min}$ until mean arterial pressure (MAP) of $40 \pm 5 \mathrm{mmHg}$ was achieved. A catheter was inserted into the bile duct. The distal end of the bile duct was ligated and the catheter was passed through the rat flank to avoid bile passage into the gut and allow the external collection of bile. The abdomen was closed. MAP of $40 \pm 5 \mathrm{mmHg}$ was maintained for $1 \mathrm{~h}$. Rats were resuscitated using shed blood and an equal volume of normal saline at the end of the shock period. HS rats underwent pentobarbital anesthesia, laparotomy, vascular cannulation, blood withdrawal and suturing but no BTED. BTED rats underwent pentobarbital anesthesia, laparotomy, vascular cannulation, bile duct cannulation and suturing but no blood withdrawal. Sham rats underwent pentobarbital anesthesia, laparotomy, vascular cannulation and suturing, but no blood withdrawal or BTED. A total of 6 rats in each group was euthanized by rapid decapitation $6 \mathrm{~h}$ after resuscitation. Segments of jejunum $(5 \mathrm{~cm}$ distal to the ligament of Treitz), ileum $(2 \mathrm{~cm}$ proximal to the cecum) and liver were harvested.

$R T-q P C R$. Jejunum, ileum and liver scrapings from all animals were snap frozen and stored at $-80^{\circ} \mathrm{C}$ for RT-qPCR. Total RNA was extracted from the jejunum, ileum and liver using TRIzol ${ }^{\circledR}$ reagent. Aliquots $(2 \mu \mathrm{g})$ of total RNA were used to synthesize complementary (c)DNA. Purity and content of RNA was determined using ultraviolet spectrophotometry. RT was performed with $0.5 \mu \mathrm{g}$ RNA to obtain cDNA in a mixture containing random primers, RevertAid Reverse Transcriptase, RNase inhibitor, and dNTPs. The PCR reaction mixture was prepared using SYBR Premix Ex Taq (Thermo Fisher Scientific, Inc.) with specific upstream and downstream primers. The thermocycling conditions were as follows: Initial denaturation for $10 \mathrm{sec}$ at $95^{\circ} \mathrm{C}$ followed by 40 cycles of $95^{\circ} \mathrm{C}$ for $5 \mathrm{sec}$ and $60^{\circ} \mathrm{C}$ for $20 \mathrm{sec}$ in a real-time PCR system (7500; Applied Biosystems; Thermo Fisher Scientific, Inc.). Relative target gene expression was quantitated according to the comparative $2^{-\Delta \Delta C q}$ method (33) and normalized to the endogenous control gene, $\beta$-actin. The primers used are listed in Table I.

Western blotting. Scrapings of the jejunum, ileum and liver from all animals were snap frozen and stored at $-80^{\circ} \mathrm{C}$ for western blotting. RIPA lysis buffer and $5 \mathrm{X}$ loading buffer were prepared. Briefly, samples were homogenized in RIPA lysis buffer supplemented with a protease inhibitor cocktail. Tissues were frozen immediately in liquid nitrogen and placed in a mortar for pulverization. Total protein was extracted by centrifuging the tubes at $4^{\circ} \mathrm{C}$ for $30 \mathrm{~min}$ at $10,000 \mathrm{x}$ g to remove debris. Protein concentration was measured using a BCA Protein Assay kit according to the manufacturer's instructions. A total of $10 \mathrm{mg}$ protein/lane was loaded onto $10 \%$ sodium dodecyl sulfate/polyacrylamide electrophoresis gel for separation, and the proteins were transferred for $2 \mathrm{~h}$ to PVDF membranes. Then membranes were blocked in 5\% skimmed milk powder at room temperature for $2 \mathrm{~h}$. The blot was probed with primary antibody overnight at $4^{\circ} \mathrm{C}$. Primary antibodies were rabbit polyclonal anti-FXR (cat. no. ab28676) and anti-TGR-5 (both 1:500; cat. no. ab72608; both Abcam) and mouse monoclonal anti- $\beta$-actin (Santa Cruz Biotechnology, Inc.; cat. no. sc517582) $(1: 1,000)$. The blots were incubated with horseradish peroxidase-conjugated goat anti-Rabbit (cat. no. BS13278) or anti-mouse (cat. no. BS12471) IgG (both 1:2,000; both Bioworld Technology, Inc.) for $2 \mathrm{~h}$ at room temperature and reacted with enhanced chemiluminescence substrate. The chemiluminescence was recorded using an imaging system (Imagequant LAS 400; GE Healthcare). The enhanced chemiluminescence signals were digitized using Photoshop CS6 software (Adobe Systems, Inc.) to quantify the expression levels of FXR, TGR-5 and $\beta$-actin. Relative FXR and TGR-5 protein expression was normalized to $\beta$-actin.

Immunohistochemistry. Samples were fixed in 4\% paraformaldehyde for $24 \mathrm{~h}$ at room temperature. The tissue was embedded in paraffin and sections $(4 \mu \mathrm{m})$ were used for immunohistochemical staining. Sections were deparaffinized, rehydrated and incubated with $3 \%$ hydrogen peroxide to quench any endogenous peroxidase activity. Sections were placed in 3\% citrate buffer to repair antigens. The buffer was heated to $92-98^{\circ} \mathrm{C}$ using a microwave for $10 \mathrm{~min}$. Sections were cooled to room temperature. The tissue samples were blocked with $5 \%$ bovine serum (Wuhan Boster Biological Technology. Ltd.) for $20 \mathrm{~min}$ at room temperature. Sections were incubated overnight at $4^{\circ} \mathrm{C}$ with optimally diluted primary antibody. Negative control sections were incubated overnight at $4^{\circ} \mathrm{C}$ with saline solution. Primary antibodies were rabbit polyclonal anti-FXR (cat. no. ab28676) and anti-TGR-5 (cat. no. ab72608; both 1:100; both Abcam). Sections were washed with PBS and incubated with goat anti-Rabbit IgG (Bioworld Technology, Inc.; cat. no. BS13278; 
Table I. Primers for reverse transcription-quantitative PCR analysis.

\begin{tabular}{lll}
\hline Gene & Forward primer, $5^{\prime} \rightarrow 3^{\prime}$ & Reverse primer, $5^{\prime} \rightarrow 3^{\prime}$ \\
\hline FXR & GTGACAAAGAAGCCGCGAAT & GCAGGTGAGCGCGTTGTAAT \\
TGR5 & CCACCACTAGGGCCTGTAAC & TCCTCGAAGCACTTGTAGCC \\
$\beta$-actin & GCGCTCGTCGTCGACAACGG & GTGTGGTGCCAAATCTTCTCC
\end{tabular}

FXR, farnesoid X receptor; TGR5, Takeda G-protein coupled receptor 5.

1:200) at room temperature for $30 \mathrm{~min}$, rewashed and incubated with peroxidase-conjugated streptavidin at room temperature for 15 min. Peroxidation activity was visualized via incubation with a peroxidase substrate solution (DAB kit; Invitrogen; Thermo Fisher Scientific, Inc.) at room temperature for $3 \mathrm{~min}$ according to the manufacturer's instructions. Sections were counterstained with hematoxylin at room temperature for $5 \mathrm{~min}$. Image-Pro Plus software 4.0 (Media Cybernetics, Inc.) was used to determine the integrated optical density of images. A total of six randomly selected fields of view/section were observed under a light microscope at x100 magnification (six sections/group).

Reagents. RIPA lysis buffer, BCA Protein Assay kit and 5X loading buffer were purchased from Beyotime Institute of Biotechnology. Rabbit polyclonal anti-FXR (cat. no. ab28676) and anti-TGR-5 (cat. no. ab72608) were purchased from Abcam. The mouse monoclonal antibody to $\beta$-actin (cat. no. sc517582) was purchased from Santa Cruz Biotechnology, Inc. The goat anti-Rabbit IgG (cat. no. BS13278) and goat anti-Mouse IgG (cat. no. BS12471) were purchased from Bioworld Technology, Inc. eECL Western Blot kit (cat. no. CW0049A) was purchased from CoWin Biosciences. RevertAidFirst Strand cDNA Synthesis kit was purchased from Thermo Fisher Scientific, Inc. SYBR Premix Ex Taq was purchased from Thermo Fisher Scientific, Inc. The primers were synthesized by Invitrogen (Thermo Fisher Scientific, Inc.). The fluorescence RT-qPCR kit was purchased from Takara Biotechnology, Co., Ltd. TRIzol ${ }^{\circledR}$ and the immunohistochemistry kit were purchased from Invitrogen (Thermo Fisher Scientific, Inc.). The $5 \%$ bovine serum was purchased from Wuhan Boster Biological Technology. Ltd.

Statistical analysis. Data were analyzed using SPSS 16.0 software (SPSS, Inc.). All data are expressed as the mean \pm SEM $(n=6)$. Results were compared by one-way analysis of variance followed by post hoc Tukey's test. $\mathrm{P}<0.05$ was considered to indicate a statistically significant difference.

\section{Results}

$R T-q P C R$. The expression levels of FXR mRNA increased significantly in the jejunum and liver and decreased significantly in the ileum following $\mathrm{HS}(\mathrm{P}<0.05$; Fig. 1). The expression levels of FXR increased significantly in the jejunum and ileum and decreased significantly in the liver following BTED $(\mathrm{P}<0.05$; Fig. 1). In HS rats, BTED significantly increased the expression levels of FXR mRNA in the jejunum and ileum but decreased these levels in the liver $(\mathrm{P}<0.05$; Fig. 1). The expression levels of TGR-5 mRNA increased significantly in the jejunum, ileum and liver following HS ( $P<0.05$; Fig. 1). The expression levels of TGR-5 decreased significantly in the jejunum, ileum and liver following BTED ( $\mathrm{P}<0.05$; Fig. 1). In HS rats, BTED significantly decreased the expression levels of TGR-5 mRNA in the jejunum, ileum and liver $(\mathrm{P}<0.05$; Fig. 1).

Western blotting. The protein expression levels of FXR increased significantly in the jejunum and liver following HS ( $\mathrm{P}<0.05$; Fig. 2). The protein expression levels of FXR increased significantly in the jejunum and ileum and decreased significantly in the liver following BTED ( $<<0.05$; Fig. 2). In HS rats, BTED significantly increased protein expression levels of FXR in the jejunum and ileum and decreased these levels in the liver ( $\mathrm{P}<0.05$; Fig. 2). The expression levels of TGR-5 increased significantly in the jejunum, ileum and liver following HS ( $\mathrm{P}<0.05$; Fig. 2). The expression levels of TGR-5 decreased significantly in the jejunum, ileum and liver following BTED ( $\mathrm{P}<0.05$; Fig. 2). In HS rats, BTED significantly decreased protein expression levels of TGR-5 in the jejunum, ileum and liver $(\mathrm{P}<0.05$; Fig. 2$)$.

Immunohistochemistry. The protein expression levels of FXR increased significantly in the liver and decreased significantly in the ileum following HS ( $\mathrm{P}<0.05$; Fig. 3 ). The protein expression levels of FXR increased significantly in the jejunum and ileum and decreased significantly in the liver following BTED $(\mathrm{P}<0.05$; Fig. 3). In HS rats, BTED significantly increased protein expression levels of FXR in the jejunum and ileum and decreased these levels in the liver $(\mathrm{P}<0.05$; Fig. 3$)$.

The protein expression levels of TGR-5 increased significantly in the jejunum and liver following HS ( $\mathrm{P}<0.05$; Fig. 4). The protein expression levels of TGR-5 decreased significantly in the jejunum, ileum and liver following BTED ( $\mathrm{P}<0.05$; Fig. 4). In HS rats, BTED significantly decreased protein expression levels of TGR-5 in the jejunum, ileum and liver ( $\mathrm{P}<0.05$; Fig. 4).

\section{Discussion}

Following fluid resuscitation in shock, cells are liberated from ischemia and hypoxia and the body begins tissue repair (34). The present study showed that mRNA and protein expression levels of FXR increased significantly in the jejunum and liver and those of TGR-5 increased significantly in the jejunum, ileum and liver following HS. This may be due to elimination of ischemia following fluid resuscitation in HS. Cell repair and regeneration increase expression levels of FXR and TGR-5. In the enterohepatic circulation, bile acid is reabsorbed in 

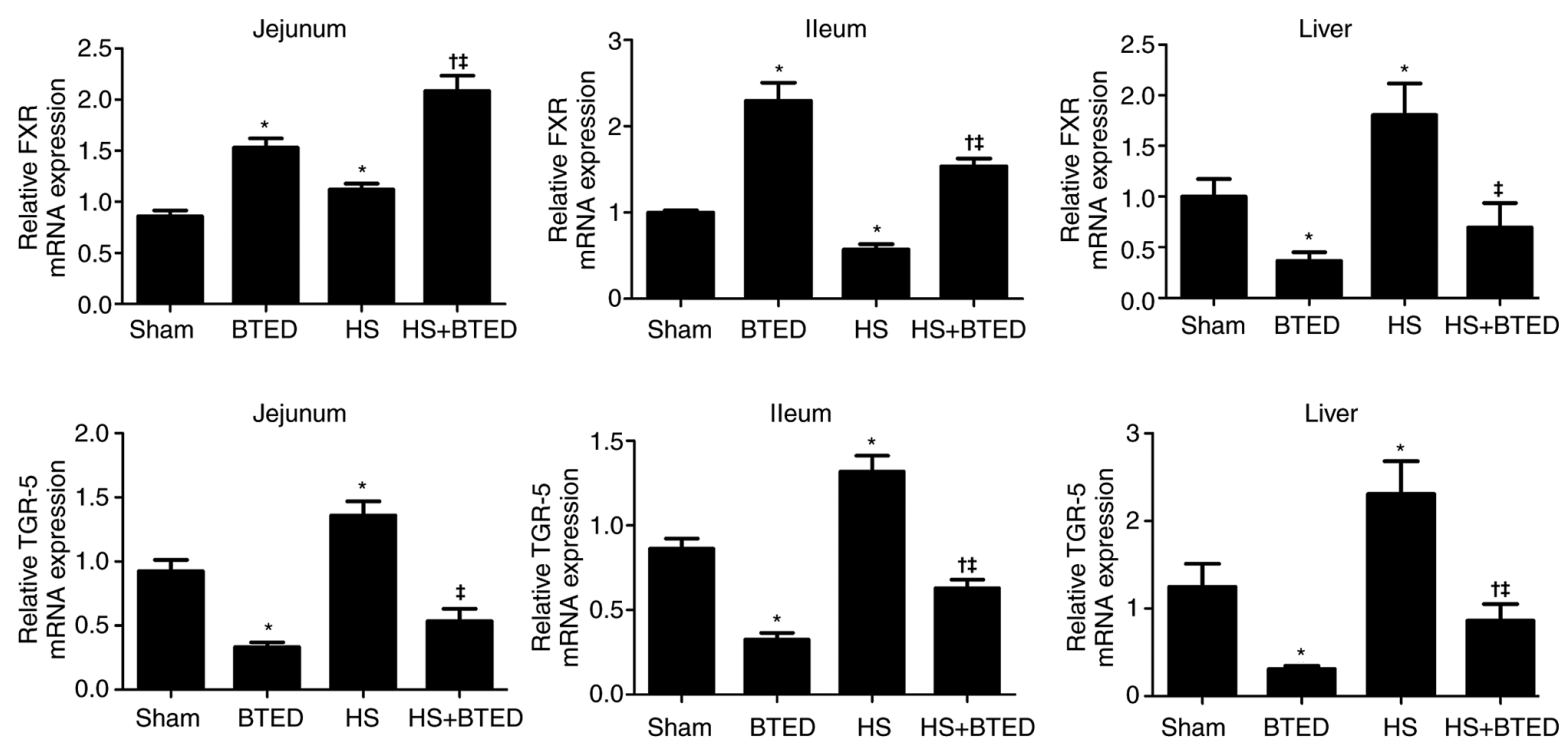

Figure 1. Expression levels of FXR and TGR-5 mRNA in the jejunum, ileum and liver. Results are presented as the mean $\pm \mathrm{SEM}(\mathrm{n}=6)$. ${ }^{*} \mathrm{P}<0.05$ vs. Sham; ${ }^{\dagger} \mathrm{P}<0.05$ vs. BTED; ${ }^{\ddagger} \mathrm{P}<0.05$ vs. HS. HS, hemorrhagic shock; BTED, biliary tract external drainage; FXR, farnesoid X receptor; TGR-5, Takeda G-protein coupled receptor 5 .
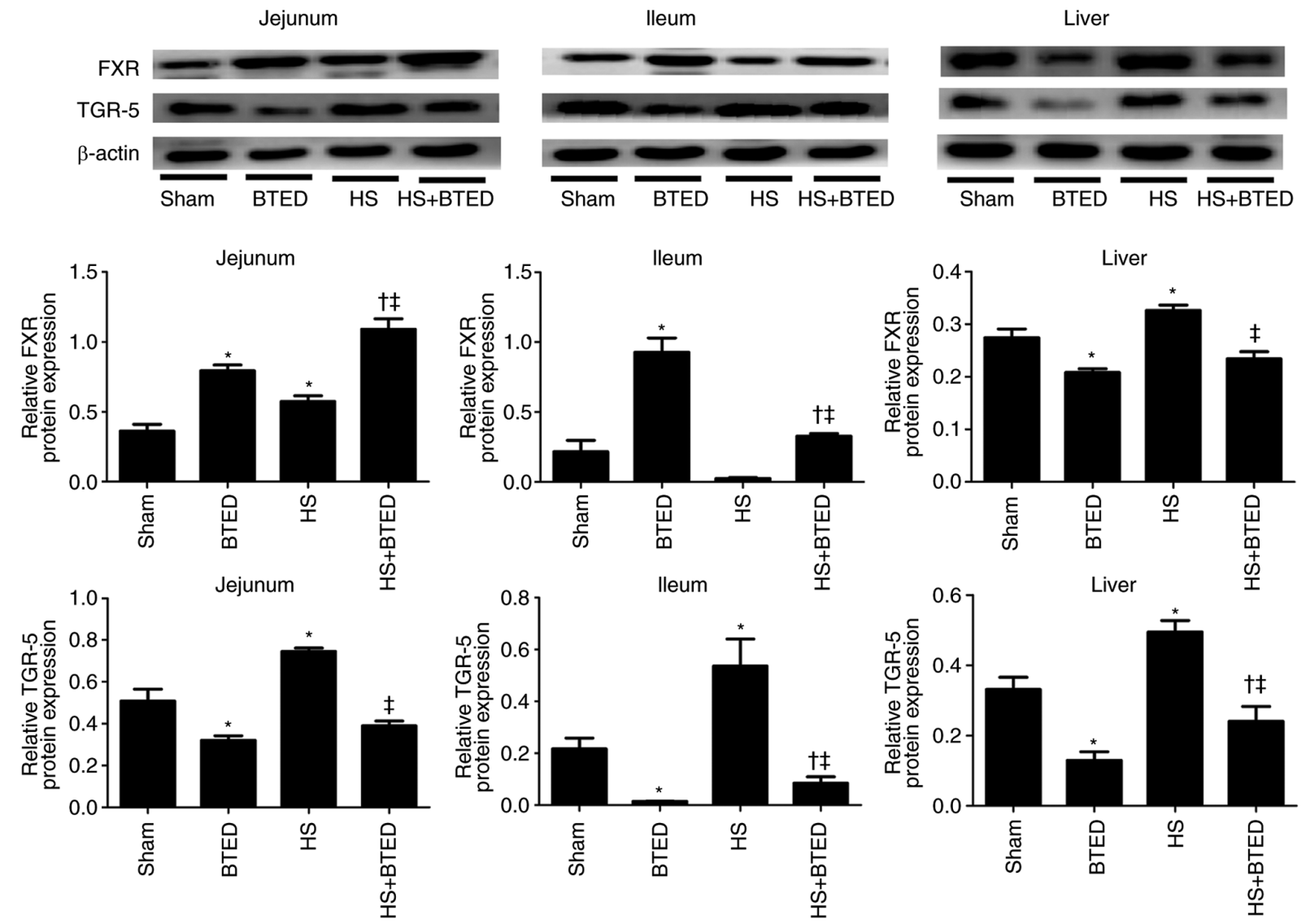

Figure 2. Protein expression levels of FXR and TGR-5 in the jejunum, ileum and liver. Results are presented as the mean \pm SEM $(n=6)$. ${ }^{*}<0.05$ vs. Sham; ${ }^{\dagger} \mathrm{P}<0.05$ vs. BTED; ${ }^{*} \mathrm{P}<0.05$ vs. HS. HS, hemorrhagic shock; BTED, biliary tract external drainage; FXR, farnesoid X receptor; TGR-5, Takeda G-protein coupled receptor 5 .

the ileum. Increased reabsorption of bile acid during HS may inhibit expression of FXR (35), which may partly explain why FXR was not upregulated in the ileum following HS in the present study.
BTED is increasingly used to treat patients with shock (36). The present study aimed to identify pathophysiological changes following BTED in HS. In addition to its therapeutic potential, BTED also exerts certain negative effects. Sinusoids 
A

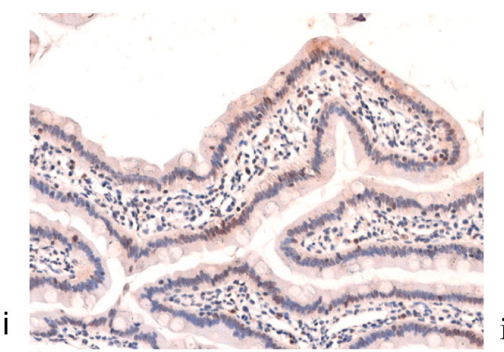

i

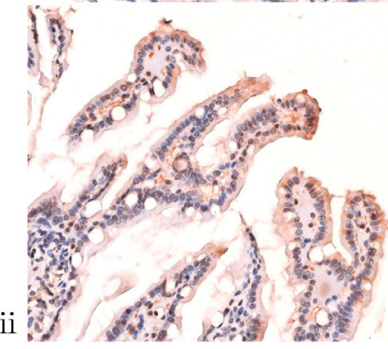

B

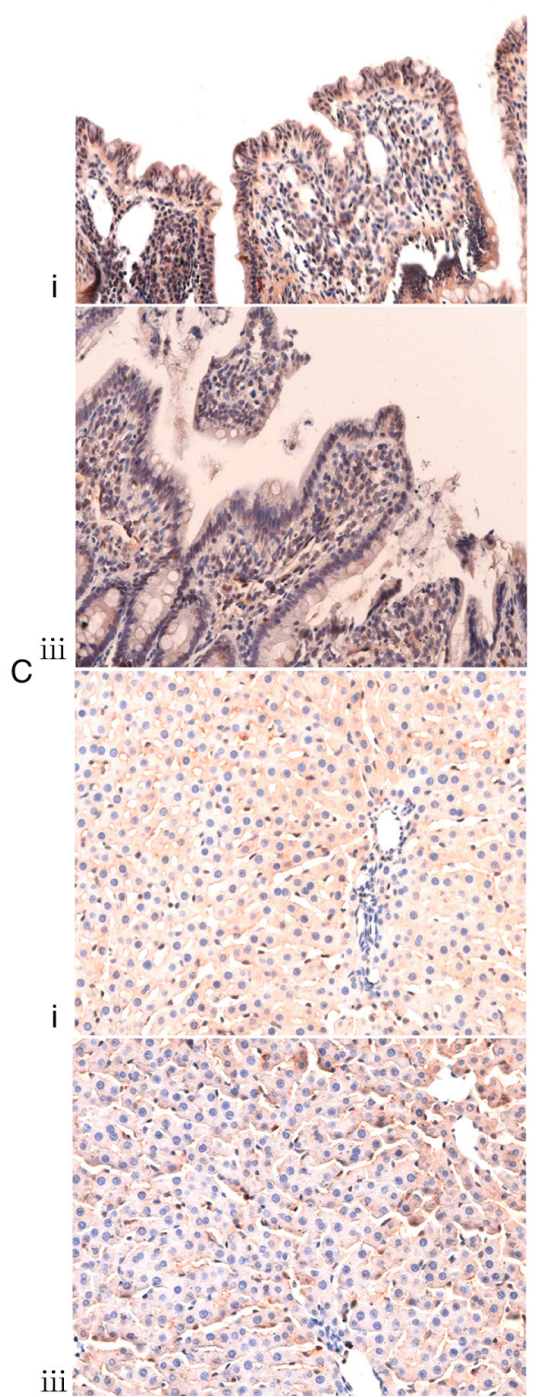

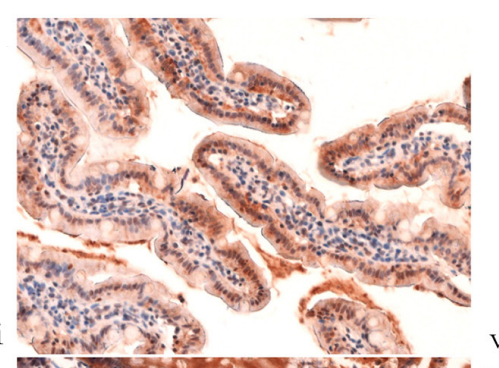
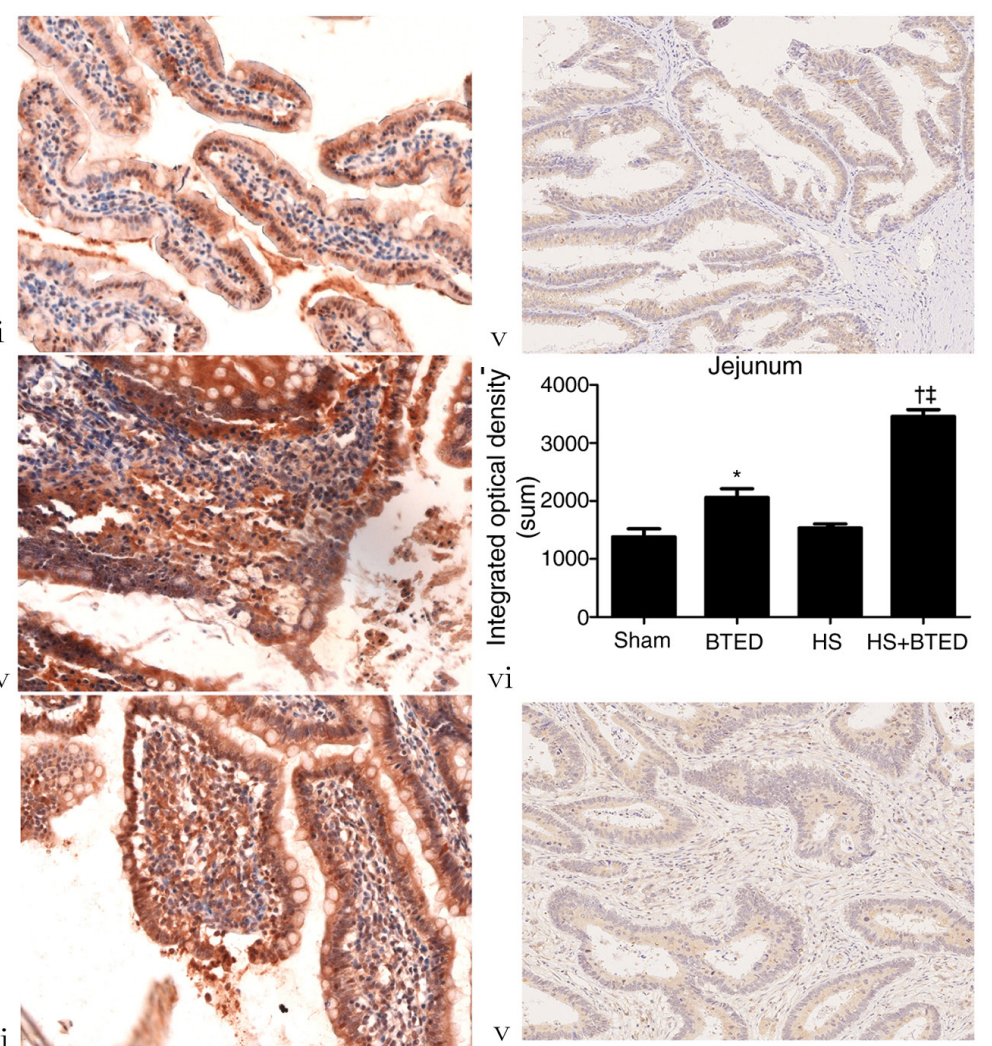

Ileum

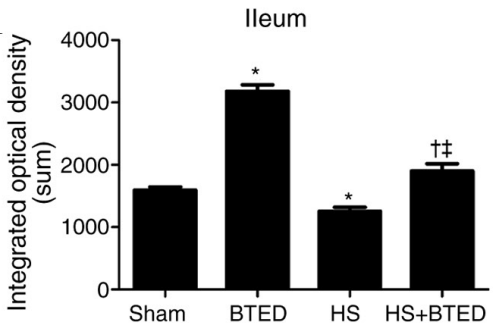

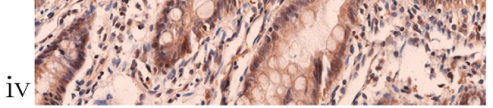
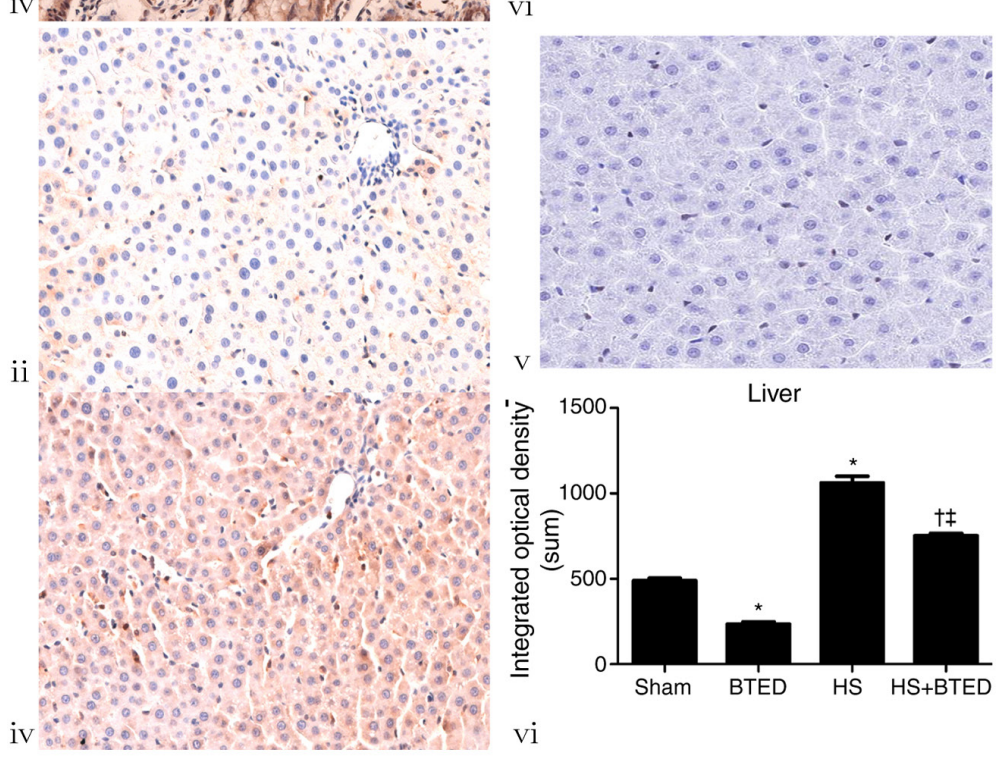

Figure 3. Immunohistochemical expression of FXR in the jejunum, ileum and liver. Immunohistochemical analysis of FXR expression in (A) jejunum, (B) ileum and (C) liver tissue. (i) Sham. (ii) BTED (iii) HS. (iv) HS+BTED. (v) Negative control. (vi) Integrated optical density. Magnification, x100. Results are presented as the mean \pm SEM $(n=6)$. ${ }^{*} \mathrm{P}<0.05$ vs. Sham; ${ }^{\circ} \mathrm{P}<0.05$ vs. BTED; ${ }^{*} \mathrm{P}<0.05$ vs. HS. HS, hemorrhagic shock; BTED, biliary tract external drainage; FXR, farnesoid X receptor.

remain narrowed due to swelling of activated Kupffer cells, which causes deterioration of hepatic microcirculation during the early phase of BTED in jaundiced mice (37). Initial liver regeneration following major hepatectomy is decreased 

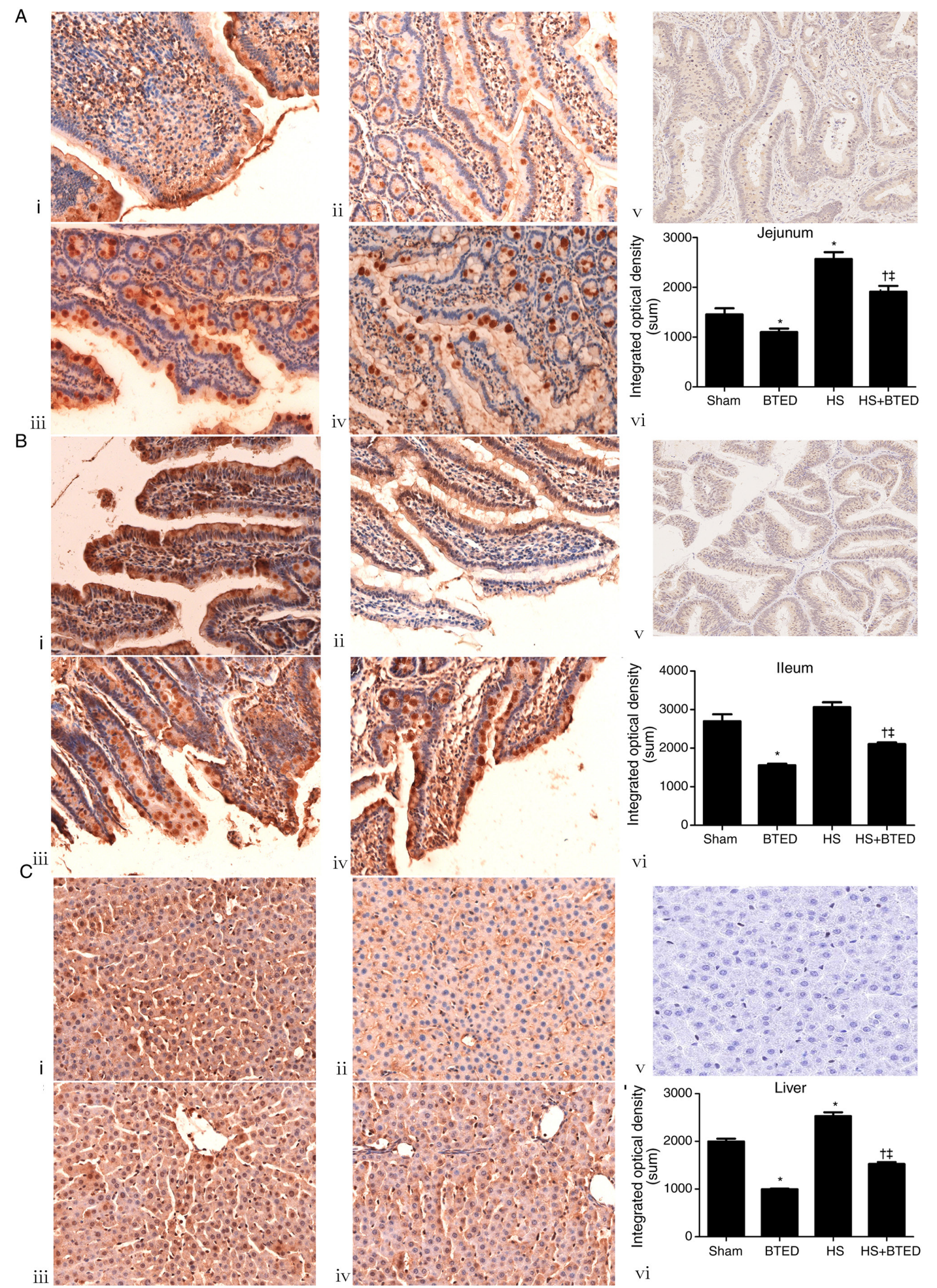

vi

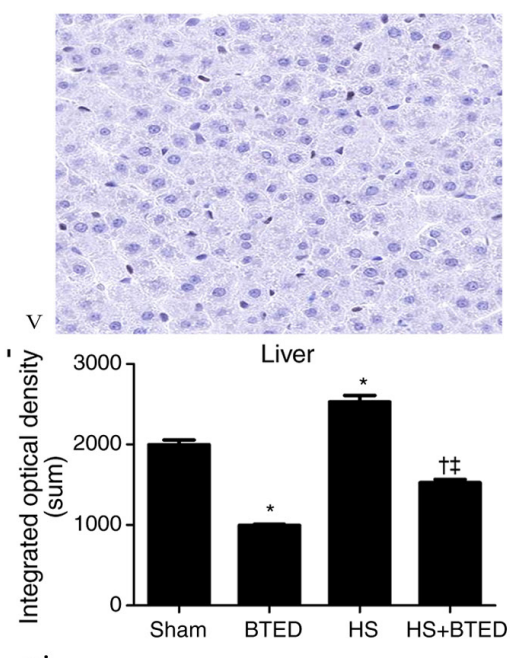

Figure 4. Immunohistochemical expression of TGR-5 in the jejunum, ileum and liver. Immunohistochemical analysis of TGR-5 expression in (A) jejunum, (B) ileum and (C) liver tissue. (i) Sham. (ii) BTED (iii) HS. (iv) HS+BTED. (v) Negative control. (vi) Integrated optical density. Magnification, x100. Results are presented as the mean \pm SEM $(n=6) .{ }^{*} \mathrm{P}<0.05$ vs. Sham; ${ }^{\dagger} \mathrm{P}<0.05$ vs. BTED; ${ }^{\dagger} \mathrm{P}<0.05$ vs. HS. HS, hemorrhagic shock; BTED, biliary tract external drainage; TGR-5, Takeda G-protein coupled receptor 5.

following biliary drainage and is associated with decreased serum bile acid levels (38). BTED as a treatment for obstructive jaundice markedly suppresses liver regeneration following partial hepatectomy (39). However, internal biliary drainage 
does not suppress regeneration of rat liver following partial hepatectomy (16). In our unpublished studies, liver damage was aggravated following BTED in a rat model of HS. Preoperative bile replacement using large volumes of bile improves blood coagulation and cellular immunity in patients with jaundice treated with BTED (40). FXR and TGR-5 serve a key role in pathophysiological changes of the liver (41). Bile acid promotes liver regeneration via FXR signaling in rats (42). Sirtuin1 controls liver regeneration by regulating bile acid metabolism via FXR (43). TGR-5 regulates bile acid hydrophobicity and stimulates bile acid excretion in urine during liver regeneration (44). BTED may affect liver function by decreasing cholic acid levels (39). To the best of our knowledge, however, the number of studies on changes in bile acid receptors following BTED in shock is limited. Therefore, the present study aimed to assess changes in FXR and TGR-5 expression in the jejunum, ileum and liver following BTED in HS rats. BTED significantly decreased the expression levels of FXR and TGR-5 in the liver in HS rats. This may be because BTED disrupts cholic acid enterohepatic circulation, thereby decreasing levels of cholic acid in the body (45). Due to lack of stimulation, levels of FXR and TGR-5 decrease, resulting in inhibition of tissue repair and liver cell regeneration The aforementioned results suggested that bile acid supplementation may be beneficial for patients receiving BTED during HS. In HS rats, BTED significantly increased expression levels of FXR but decreased those of TGR-5 in the jejunum and ileum. This may explain why BTED does not cause injury to the jejunum and ileum.

The present study is only a preliminary observation and the clinical significance of the effect of BTED on FXR and TGR-5 in HS is unclear. For example, FXR and TGR-5 promote organ regeneration $(46,47)$. However, the effect of BTED on expression levels of proliferation markers is unclear. The association between BTED and organ regeneration should be investigated in future experiments.

In summary, the expression levels of FXR and TGR-5 changed following BTED in HS. BTED significantly increased expression levels of FXR in the jejunum and ileum but decreased FXR expression in the liver in HS rats. BTED significantly decreased expression levels of TGR-5 in the jejunum, ileum and liver in HS rats.

\section{Acknowledgements}

Not applicable.

\section{Funding}

The present study was supported by the National Natural Science Fund of China (grant no. 81801901).

\section{Availability of data and materials}

The datasets used and/or analyzed during the current study are available from the corresponding author on reasonable request.

\section{Authors' contributions}

LW, HWH, XZ and YL drafted the manuscript. LW and HWH performed surgical procedures. LW and $\mathrm{HWH}$ performed statistical analysis. XZ and YL conceived and designed the study. LW and XZ confirm the authenticity of all the raw data. All authors read and approved the final manuscript.

\section{Ethics approval and consent to participate}

The present study was approved by the Institutional Animal Care and Use Committee at Peking Union Medical College (Beijing, China).

\section{Patient consent for publication}

Not applicable.

\section{Competing interests}

The authors declare that they have no competing interests.

\section{Authors' information}

LW, ORCID no. 0000-0001-6553-6381; HWH, ORCID no. 0000-0003-3422-3109; XZ, ORCID no. 0000-0001-85238082; YL, ORCID no. 0000-0003-0274-8322.

\section{References}

1. Wiener G, Moore HB, Moore EE, Gonzalez E, Diamond S, Zhu S, D'Alessandro A and Banerjee A: Shock releases bile acid inducing platelet inhibition and fibrinolysis. J Surg Res 195: 390-395, 2015.

2. Bertók L: Role of endotoxins and bile acids in the pathogenesis of septic circulatory shock. Acta Chir Hung 36: 33-36, 1997.

3. Engler S, Elsing C, Flechtenmacher C, Theilmann L, Stremmel W and Stiehl A: Progressive sclerosing cholangitis after septic shock: A new variant of vanishing bile duct disorders. Gut 52: 688-693, 2003.

4. Luyer MD, Buurman WA, Hadfoune M, Jacobs JA, Dejong CH and Greve JW: High-fat enteral nutrition reduces endotoxin, tumor necrosis factor-alpha and gut permeability in bile duct-ligated rats subjected to hemorrhagic shock. J Hepatol 41: 377-383, 2004.

5. Xu C, Huang XE, Wang SX, Lv PH, Sun L and Wang FA: Comparison of infection between internal-external and external percutaneous transhepatic biliary drainage in treating patients with malignant obstructive jaundice. Asian Pac J Cancer Prev 16: 2543-2546, 2015.

6. Saettini F, Agazzi R, Giraldi E, Foglia C, Cavalleri L, Morali L, Fasolini G, Spotti A and Provenzi M: Percutaneous transhepatic biliary drainage in an infant with obstructive jaundice caused by neuroblastoma. Pediatr Hematol Oncol 32: 223-228, 2015.

7. Arkadopoulos N, Kyriazi MA, Papanikolaou IS, Vasiliou P, Theodoraki K, Lappas C, Oikonomopoulos N and Smyrniotis V: Preoperative biliary drainage of severely jaundiced patients increases morbidity of pancreaticoduodenectomy: Results of a case-control study. World J Surg 38: 2967-2972, 2014

8. Shinya S, Sasaki T, Yamashita Y, Kato D, Yamashita K, Nakashima R, Yamauchi Y and Noritomi T: Procalcitonin as a useful biomarker for determining the need to perform emergency biliary drainage in cases of acute cholangitis. J Hepatobiliary Pancreat Sci 21: 777-785, 2014.

9. McNabb-Baltar J, Trinh QD and Barkun AN: Biliary drainage method and temporal trends in patients admitted with cholangitis: A national audit. Can J Gastroenterol 27: 513-518, 2013.

10. Itoi T, Tsuyuguchi T, Takada T, Strasberg SM, Pitt HA, Kim MH, Belli G, Mayumi T, Yoshida M, Miura F, et al: TG13 indications and techniques for biliary drainage in acute cholangitis (with videos). J Hepatobiliary Pancreat Sci 20: 71-80, 2013.

11. Abdelkader AM, Zidan AM and Younis MT: Temporary CBD stenting with a nelaton tube is a more practical and safer option than T-tube drainage after conventional CBD exploration for choledocholithiasis. HPB Surg 2018: 8035164, 2018. 
12. Wang L, Zhao B, Chen Y, Ma L, Chen EZ and Mao EQ: Biliary tract external drainage protects against intestinal barrier injury in hemorrhagic shock rats. World J Gastroenterol 21: 12800-12813, 2015.

13. Wang L, Zhao B, Chen Y, Ma L, Chen EZ and Mao EQ: Inflammation and edema in the lung and kidney of hemorrhagic shock rats are alleviated by biliary tract external drainage via the heme oxygenase-1 pathway. Inflammation 38: 2242-2251, 2015.

14. Wang L, Zhao B, Chen Y, Ma L, Chen EZ and Mao EQ: Biliary tract external drainage increases the expression levels of heme oxygenase-1 in rat livers. Eur J Med Res 20: 61, 2015.

15. Wang L, Zhao B, Chen Y, Ma L, Chen EZ and Mao EQ: Biliary tract external drainage alleviates kidney injury in shock. J Surg Res 199: 564-571, 2015.

16. Suzuki H, Iyomasa S, Nimura Y and Yoshida S: Internal biliary drainage, unlike external drainage, does not suppress the regeneration of cholestatic rat liver after partial hepatectomy. Hepatology 20: 1318-1322, 1994.

17. Iracheta-Vellve A, Calenda CD, Petrasek J, Ambade A, Kodys K Adorini L and Szabo G: FXR and TGR5 agonists ameliorate liver injury, steatosis, and inflammation after binge or prolonged alcohol feeding in mice. Hepatol Commun 2: 1379-1391, 2018.

18. Mertens KL, Kalsbeek A, Soeters MR and Eggink HM: Bile acid signaling pathways from the enterohepatic circulation to the central nervous system. Front Neurosci 11: 617, 2017.

19. Wang YD, Chen WD, Moore DD and Huang W: FXR: A metabolic regulator and cell protector. Cell Res 18: 1087-1095, 2008.

20. Lee FY, Lee H, Hubbert ML, Edwards PA and Zhang Y: FXR, a multipurpose nuclear receptor. Trends Biochem Sci 31: 572-580, 2006.

21. Horikawa T, Oshima T, Li M, Kitayama Y, Eda H, Nakamura K, Tamura A, Ogawa T, Yamasaki T, Okugawa T, et al: Chenodeoxycholic acid releases proinflammatory cytokines from small intestinal epithelial cells through the farnesoid $X$ receptor. Digestion 100: 286-294, 2019.

22. Tuominen I and Beaven SW: Intestinal farnesoid X receptor puts a fresh coat of wax on fatty liver. Hepatology 62: 646-648, 2015

23. Hou Y, Fan W, Yang W, Samdani AQ, Jackson AO and Qu S: Farnesoid $\mathrm{X}$ receptor: An important factor in blood glucose regulation. Clin Chim Acta 495: 29-34, 2019.

24. Meng Q, Chen X, Wang C, Liu Q, Sun H, Sun P, Peng J and Liu K: Alisol B 23-acetate promotes liver regeneration in mice after partial hepatectomy via activating farnesoid X receptor. Biochem Pharmacol 92: 289-298, 2014.

25. Zhang L, Wang YD, Chen WD, Wang X, Lou G, Liu N, Lin M, Forman BM and Huang W: Promotion of liver regeneration/repair by farnesoid X receptor in both liver and intestine in mice. Hepatology 56: 2336-2343, 2012.

26. Chen WD, Wang YD, Zhang L, Shiah S, Wang M, Yang F, Yu D, Forman BM and Huang W: Farnesoid X receptor alleviates age-related proliferation defects in regenerating mouse livers by activating forkhead box m $1 \mathrm{~b}$ transcription. Hepatology 51 : 953-962, 2010.

27. Kawamata Y, Fujii R, Hosoya M, Harada M, Yoshida H, Miwa M, Fukusumi S, Habata Y, Itoh T, Shintani Y, et al: A $\mathrm{G}$ protein-coupled receptor responsive to bile acids. J Biol Chem 278: 9435-9440, 2003.

28. Finn PD, Rodriguez D, Kohler J, Jiang Z, Wan S, Blanco E, King AJ, Chen T, Bell N, Dragoli D, et al: Intestinal TGR5 agonism improves hepatic steatosis and insulin sensitivity in Western diet-fed mice. Am J Physiol Gastrointest Liver Physiol 316: G412-G424, 2019.

29. Fiorucci S, Mencarelli A, Palladino G and Cipriani S: Bile-acid-activated receptors: Targeting TGR5 and farnesoid-X-receptor in lipid and glucose disorders. Trends Pharmacol Sci 30: 570-580, 2009.

30. Jourdainne V, Péan N, Doignon I, Humbert L, Rainteau D and Tordjmann T: The bile acid receptor TGR5 and liver regeneration. Dig Dis 33: 319-326, 2015.

31. Péan N, Doignon I, Garcin I, Besnard A, Julien B, Liu B, Branchereau S, Spraul A, Guettier C, Humbert L, et al: The receptor TGR5 protects the liver from bile acid overload during liver regeneration in mice. Hepatology 58: 1451-1460, 2013.
32. Berquist TH, May GR, Johnson CM, Adson MA and Thistle JL: Percutaneous biliary decompression: Internal and external drainage in 50 patients. AJR Am J Roentgenol 136: 901-906, 1981.

33. Livak KJ and Schmittgen TD: Analysis of relative gene expression data using real-time quantitative PCR and the 2(-Delta Delta C(T)) method. Methods 25: 402-408, 2001

34. Gordon D and Spiegel R: Fluid resuscitation: History, physiology, and modern fluid resuscitation strategies. Emerg Med Clin North Am 38: 783-793, 2020.

35. Nakatani T and Kobayashi K: Post-traumatic jaundice-its mechanism from a view point of hepatic mitochondrial function. Nihon Geka Gakkai Zasshi 92: 441-447, 1991 (In Japanese).

36. Shimada H, Nakagawara G, Kobayashi M, Tsuchiya S, Kudo T and Morita S: Pathogenesis and clinical features of acute cholangitis accompanied by shock. Jpn J Surg 14: 269-277, 1984.

37. Okaya T, Nakagawa K, Kimura F, Shimizu H, Yoshidome H, Ohtsuka M, Kato A, Yoshitomi H, Ito $\mathrm{H}$ and Miyazaki M: The alterations in hepatic microcirculation and Kupffer cell activity after biliary drainage in jaundiced mice. J Hepatobiliary Pancreat Sci 19: 397-404, 2012

38. Otao R, Beppu T, Isiko T, Mima K, Okabe H, Hayashi H, Masuda T, Chikamoto A, Takamori $\mathrm{H}$ and Baba H: External biliary drainage and liver regeneration after major hepatectomy. Br J Surg 99: 1569-1574, 2012

39. Iyomasa S, Terasaki M, Kuriki H, Nimura Y, Shionoya S, Kojima $\mathrm{K}$ and Yoshida S: Decrease in regeneration capacity of rat liver after external biliary drainage. Eur Surg Res 24: 265-272, 1992

40. Yoshida Y, Ajiki T, Ueno K, Shinozaki K, Murakami S, Okazaki T, Matsumoto T, Matsumoto I, Fukumoto T, Usami M and $\mathrm{Ku} \mathrm{Y}$ : Preoperative bile replacement improves immune function for jaundiced patients treated with external biliary drainage. J Gastrointest Surg 18: 2095-2104, 2014.

41. Ferrell JM, Pathak P, Boehme S, Gilliland T and Chiang JY: Deficiency of both farnesoid $X$ receptor and takeda $G$ protein-coupled receptor 5 exacerbated liver fibrosis in mice. Hepatology 70: 955-970, 2019.

42. Ding L, Yang Y, Qu Y, Yang T, Wang K, Liu W and Xia W: Bile acid promotes liver regeneration via farnesoid $\mathrm{X}$ receptor signaling pathways in rats. Mol Med Rep 11: 4431-4437, 2015.

43. Garcia-Rodriguez JL, Barbier-Torres L, Fernández-Álvarez S, Gutiérrez-de Juan V, Monte MJ, Halilbasic E, Herranz D, Álvarez L, Aspichueta P, Marín JJ, et al: SIRT1 controls liver regeneration by regulating bile acid metabolism through farnesoid $\mathrm{X}$ receptor and mammalian target of rapamycin signaling. Hepatology 59: 1972-1983, 2014.

44. Fan M, Wang X, Xu G, Yan Q and Huang W: Bile acid signaling and liver regeneration. Biochim Biophys Acta 1849: 196-200, 2015.

45. Sun Q, Fang F, Lu GC, Mao HH, Xu JH, Zhou SK, Tong XM, Guo Y, Wu JF and Jiang B: Effects of different drainage methods on serum bile acid and hepatocyte apoptosis and regeneration after partial hepatectomy in rats with obstructive jaundice. J Biol Regul Homeost Agents 33: 571-579, 2019.

46. Jung K, Kim M, So J, Lee SH, Ko S and Shin D: Farnesoid X receptor activation impairs liver progenitor cell-mediated liver regeneration via the PTEN-PI3K-AKT-mTOR axis in zebrafish. Hepatology 74: 397-410, 2021.

47. Chiang JYL and Ferrell JM: Bile acid receptors FXR and TGR5 signaling in fatty liver diseases and therapy. Am J Physiol Gastrointest Liver Physiol 318: G554-G573, 2020.

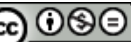

This work is licensed under a Creative Commons Attribution-NonCommercial-NoDerivatives 4.0 International (CC BY-NC-ND 4.0) License. 